\title{
Giant elasticity in the Ni-Mn-Ga single crystalline FSMA martensites
}

\author{
I. Glavatskyy ${ }^{\mathrm{a}, 1,2}$, N. Glavatska ${ }^{1}$ \\ ${ }^{1}$ Institute for Metal Physics, 36 Vernadsky blvd., Kiev 03142, Ukraine \\ ${ }^{2}$ Helmhotz Centre Berlin for Materials and Energy, Glienicker Str. 100, Berlin 14109, Germany
}

\begin{abstract}
The phenomenon of the giant elastic completely reversible linear strain is found at constant temperatures in Ni-Mn-Ga martensites. Single crystals of some off-stoichiometric Ni-Mn-Ga compositions possess rubber-like behavior in the martensite phase with completely elastic strain reaching over $10 \%$ at some $90 \mathrm{MPa}$ compressive stress at room temperature. The observed phenomenon is different from the conventional (two-phase) superelasticity, since it is found completely in the martensite phase and no intermartensitic reaction is observed during the load-unload cycling. The main features of the observed rubber-like behavior are: 1) complete elasticity and giant values of the strains achieved; 2) the linear character of stress-strain dependence; 3) excellent stability to the mechanical cycling, stress rate and temperature variation, in contrast to the conventional two-phase superelasticity due to the stress induced martensite transformation. Current work is directed to study the structural mechanisms of the found phenomenon by means of the neutron diffraction in-situ under compressive stress cycling.
\end{abstract}

\section{Introduction}

Ni-Mn-Ga alloys are well-known shape memory systems possessing thermoelastic martensitic transformation. Moreover, Ni-Mn-Ga possesses ferromagnetic ordering in martensite phase [1], thus being unique magnetic shape memory alloy (MSMA) system. Mechanical and magnetic properties of Ni-Mn-Ga alloys have been extensively studied. It was shown [2-4] that this alloy system possesses a high pseudoelastic, also called superelastic effect. However, all previously studied stress-strain loops showing pseudoelastic behaviour in these alloys, as well as in most SMA systems such as Ti-Pd-Ni [5], Ni-Ti [6,7], Fe-Pt [8], Cu-Al-X where X is $\mathrm{Mn}$, $\mathrm{Zn}$, Ni $[9,10]$ etc. are due to the stress induced martensite transformation (i.e. two-phase superelasticity), and thus, could be obtained only at temperatures above martensite transformation $\left(\mathrm{M}_{\mathrm{S}}\right)$. This relevantly limits possible technical applications, since most of the systems possessing a pseudoelastic behaviour have $\mathrm{M}_{\mathrm{S}}$ above room temperature. The conventional two-phase superelasticity in crystalline SMA possesses several major drawbacks, i.e.: highly nonlinear hysteretic behaviour, strongly dependent on the stress or deformation rates $[12,13]$, not stable with stress cycling, and with strong temperature dependence of the superelastic loop and critical stress values [4,10,11]. While the Ti-Ni [6] seems attractive having $100 \%$ recovery and a quasilinear behaviour, though it possesses small elastic strain values (4\%) at very high stress values - above $1 \mathrm{GPa}$. On the other hand, in the $20 \%$ compressive strain in the martensite phase of single crystalline Ni-Mn-Ga alloy was obtained [14]. However, the crystal faulted, thus strain in the case is not recoverable. Authors [14] obtained $8 \%$ shape-memory effect by heating above $400^{\circ} \mathrm{C}$.

We have recently observed and propose another type of superelasticity - completely in the martensite phase of the Ni-Mn-Ga alloys, thus being not temperature sensitive and quasilinear, at the same time reaching high elastic strain values with $100 \%$ recovery and stable to cycling.

\section{Experimental procedure}

Two Ni-Mn-Ga alloys of non-stoichiometric compositions (Table 1) having two main different martensite lattice types were investigated. Single crystals were grown by vertical gradient freeze technique from polycrystalline ingots, initially arc-smelt from $99.98 \%$ pure $\mathrm{Ni}, \mathrm{Mn}$ and $\mathrm{Ga}$ chips, which were 4-times sequentially remelted to achieve better chemical homogeneity. Obtained single crystals were heat treated for annealing for homogenization at $1273 \mathrm{~K}$ for 72 hours and ordering at $1070 \mathrm{~K}$ during 48 hours. All melting and heat treatment

a e-mail: illya.glavatskyy@helmholtz-berlin.de

This is an Open Access article distributed under the terms of the Creative Commons Attribution-Noncommercial License (http://creativecommons.org/licenses/by-nc/3.0/), which permits unrestricted use, distribution, and reproduction in any noncommercial medium, provided the original work is properly cited. 
procedures were carried out under in protective argon with $2 \% \mathrm{H} 2$ atmosphere. The crystal structure of the martensite phases was determined using X-ray powder diffraction (Fig.1), and orientation of the single crystal specimens was determined using a 3-circle X-Ray diffractometer with the monochromatic $\mathrm{CuK} \alpha$ radiation. Temperatures of direct $\left(\mathrm{M}_{\mathrm{S}}\right)$ and reverse $\left(\mathrm{A}_{\mathrm{S}}\right)$ martensite transformation and Curie point $\left(\mathrm{T}_{\mathrm{C}}\right)$ were determined using two standard methods: low field ac-magnetic susceptibility measurements and dilatometry (curves not shown due to limitation of the pictures number). Chemical composition, phase transformation temperatures and martensite lattice parameters are given in Table 1. For simplicity reasons we use fct martensite lattice approximation and indexing system of parent austenite phase. Single crystalline specimens were cut parallel to $\{100\}$ martensite planes and electropolished in the $25 \% \mathrm{HNO} 3+75 \%$ alcohol electrolyte. Loading speed in the experiments was $0.1-5 \mathrm{~mm} / \mathrm{min}$ (deformation rate: $\left(\mathrm{R} \sim 1 * 10^{-4}\right.$ up to $\left.8.3 * 10^{-3} \mathrm{~s}^{-1}\right)$ ). Compressive stress-strain studies were performed by using Tinius-Olsen H1K-T mechanical testing machine with specially constructed narrow blow hot air system for temperature control $(\delta \mathrm{T}= \pm 2 \mathrm{~K})$.

\section{Results and discussion}

All studied alloys possess a thermoelastic martensitic transformation, exhibiting self-accommodation twinned martensite morphology. Alloys 1 has $10 \mathrm{M}$ superstructural martensite lattice packing modulation along $\langle 110\rangle_{f c t}$ direction [15]. The martensite phase of all alloys has a strong magnetic anisotropy in the ferromagnetic state below $\mathrm{T}_{\mathrm{C}}$, i.e. for alloy 1: [001] $]_{f t}$ - axis of easy magnetization, and [010] $]_{c t}$ - hard magnetization axis; for alloy 2: $(001)_{f c t}$ - easy magnetization plane, with $[001]_{f c t}$ being axis of hard magnetization.

Table 1. Compositions, phase transformation temperatures and lattice parameters in fct martensite approximation according to the parent austenite phase.

\begin{tabular}{|c|c|c|c|c|c|c|c|c|}
\hline alloy & Composition & $\mathrm{T}_{\mathrm{c}}, \mathrm{K}$ & $\mathrm{M}_{\mathrm{s}}, \mathrm{K}$ & $\mathrm{A}_{\mathrm{s}}, \mathrm{K}$ & $\mathrm{a}, \mathrm{nm}^{*}$ & $\mathrm{c}, \mathrm{nm}^{*}$ & modulation & distortion \\
\hline 1 & $\mathrm{Ni}_{1.95} \mathrm{M}_{1.20} \mathrm{Ga}_{0.85}$ & 375 & 307 & 315 & 0.593 & 0.559 & $10 \mathrm{M},<010>_{\text {fct }}$ & $6 \%$ \\
\hline 2 & $\mathrm{Ni}_{2.13} \mathrm{Mn}_{0.78} \mathrm{Ga}_{1.09}$ & 365 & 465 & 468 & 0.540 & 0.665 & none & $23 \%$ \\
\hline
\end{tabular}

* lattice parameters are given for $T=293 \mathrm{~K}$.

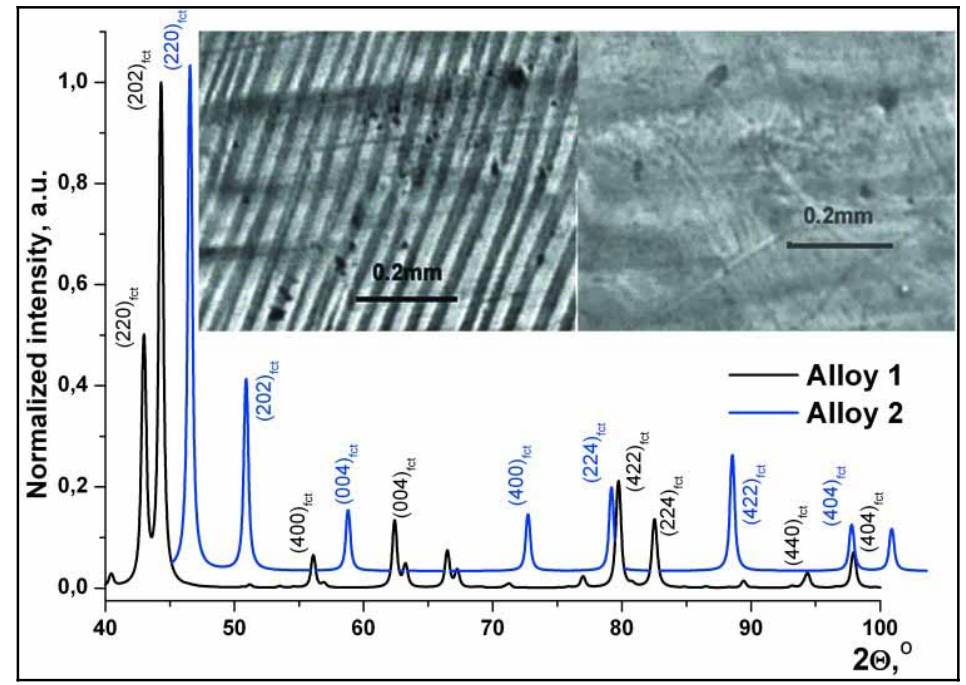

Fig.1. The X-ray powder diffraction patterns collected at $\mathrm{CuK \alpha}$ for the martensite crystal lattice determination. Indexing is given within $f c t$ approximation, according to the parent austenite phase, thus superstuctural peaks are not listed. The insert shows microstructure relief of the Alloy 1 martensite: left - initial twinned, right - detwinned after $1^{\text {st }}$ loading cycle.

All results of experiments conducted in this study are given in Figs.2-4 in engineering stress-strain coordinates, as this system shows directly the true linear elastic deformation dependence on the applied force, as it might be important for possible technical application.

Alloy 1 has a thermoelastic martensite with self-accommodation twinning system [15] with very low critical slip stress (CSS). Thus, as shown on Fig.2, the stress-strain behaviour in the $[100]_{f c t}$ direction has a "plastic" character on the $1^{\text {st }}$ cycle, the specimen was originally oriented with the $[100]_{f c t}$ axis along the stress direction. However, a stress as low as $0.8 \mathrm{MPa}$ leads to detwinning of the martensite and a reorientation of the $[001]_{f c t}$ axis in the stress direction. Further cycling, newly along the $[001]_{f c t}$ axis (being the axis of easy magnetization of the 
martensite) results in elastic deformation, which stabilizes after the $3^{\text {rd }}$ cycle, though some residual twin remains, leading to a non-linear $\sigma(\varepsilon)$ dependence. On the other hand, stress-strain cycling in the $[010]_{f c t}$ direction, being also the hard axis of magnetisation (insert on Fig.2), has a pure linear character during the loading stage, the strain is $100 \%$ reversible at room temperature and the cycling is stable reaching $4 \%$ elastic strain. The martensite $[010]_{f c t}$ axis is conserved non-twinned [15], which is also the axis of hard magnetization of the martensite. Unfortunately, the 10M-type Ni-Mn-Ga alloys family, to which belongs the studied Alloy 1, is known to be rather brittle and the specimen fails early during the continuous loading cycles.

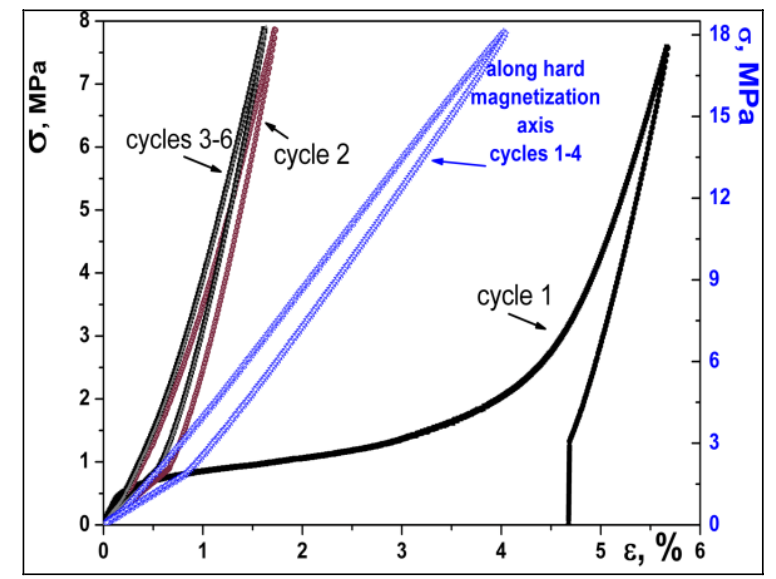

Fig.2. Stress-strain cycling loops of alloy 1 single crystal. Applied stress causes martensite twin variant reorientation, resulting in change of crystallographic direction from [100] in the $1^{\text {st }}$ cycle to [001] in the latter: $\varepsilon=1.6 \%$ elastic strain obtained. The blue curve shows stress-strain cycling loops of alloy 1 single crystal measured along the "hard magnetization" direction [010]. Strain rate $-1 \mathrm{~mm} / \mathrm{min}\left(\mathrm{R}=1.15^{*} 10^{-4} \mathrm{~s}^{-1}\right)$, at $\mathrm{T}=295 \mathrm{~K}$.

In alloy 2 single crystal, we observe (Fig.3) twin variant reorientation under the applied stress during the first loading cycle, in the same manner as on Fig. 2 for alloy 1. However, the CSS in alloy $2(\sim 14 \mathrm{MPa})$ is more then order of magnitude higher than in alloy $1(0.6 \mathrm{MPa})$. Starting with the second cycle, we obtain a $100 \%$ reversible superelastic deformation strain of $15.4 \%$ at room temperature. Further cycling demonstrates absolute stability and repeatability of the superelastic stress-strain loop (cycles 1-10 of total 50 performed cycles are shown, since later cycling loops looks identical).

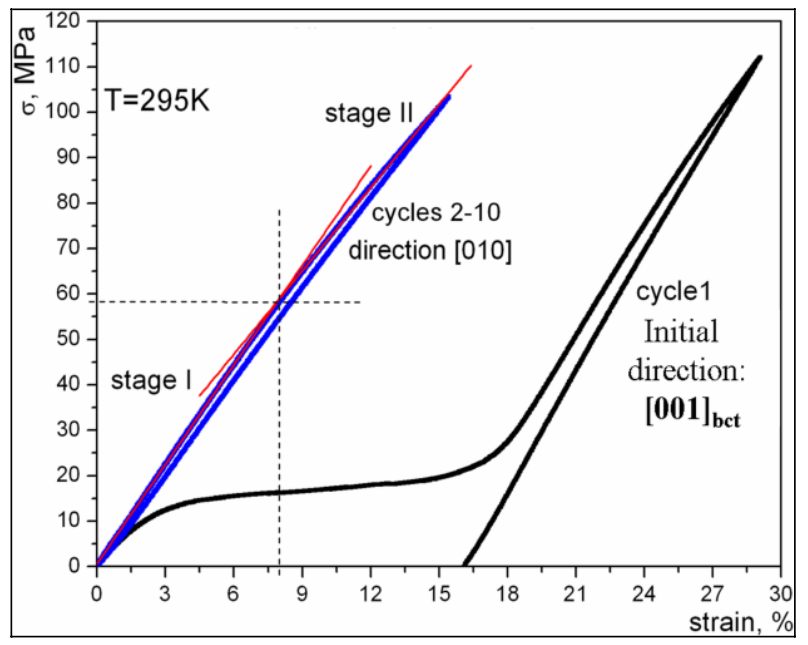

Fig.3. Alloy 2 single crystal elastic stress-strain cycling: absolutely elastic $\varepsilon=15.4 \%$ strain achieved at the $2^{\text {nd }}$ cycle. Strain rate: $1 \mathrm{~mm} / \mathrm{min}\left(\mathrm{R}=1 * 10^{-4} \mathrm{~s}^{-1}\right), \mathrm{T}=295 \mathrm{~K}$.

Closer analysis of the loading phase on alloy 2 reveals that it could be approximated with high confidence ( $\mathrm{r}>$ 0.998 ) by two linear parts $-1^{\text {st }}$ from $0 \%$ to about an $8 \%$ deformation, and $2^{\text {nd }}-$ from $8 \%$ till the end of the cycle. Stage I seem to correspond to the eigen-elastic deformation, while stage II is believed to be due to a stress induced nucleation and growth of another metastable elastic accommodative hierarchical twinning of martensite, incorporating micro- and nano- scales, which decapsulates with stress removal. Such possibility is considered based on the results obtained by V. L'vov and V. Chernenko in [16], that axe-symmetric compression induces the xy-twinned structure of martensite. The critical stress is found to be about $60 \mathrm{MPa}$ at an $8 \%$ deformation. The 
observed behavior is somewhat analogous to the TiPdNi superelasticity presented in [4], though with a cardinal difference: in our case we observe the superelastic behavior completely in the martensite phase. The unloading stage is linear over the whole range, unlike in [4]. Again, the best superelastic behavior is attributed to the hard magnetization direction. Thus, we can emphasize the clear correlation with the magnetic anisotropy of the martensite, namely the axis of hard magnetization, exhibiting a giant linear rubber-like behavior.

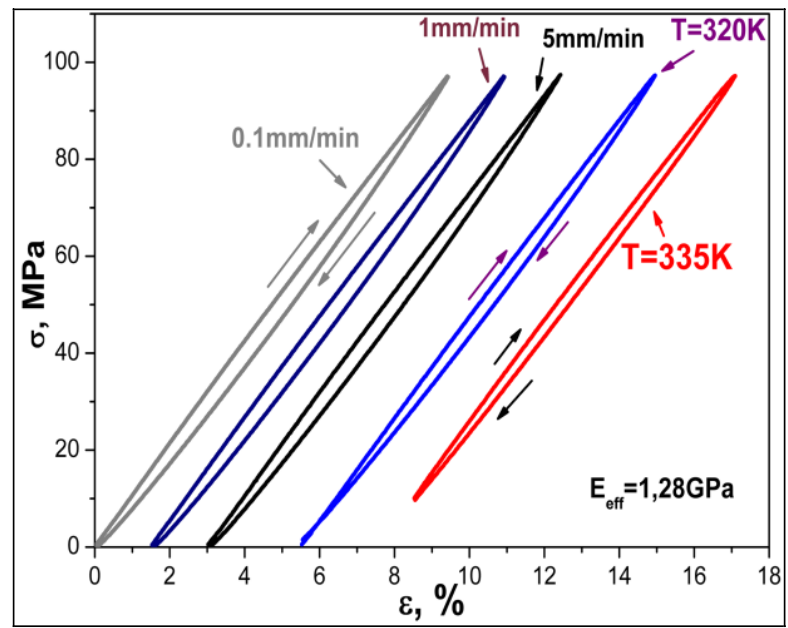

Fig.4. Alloy 2 single crystal elastic loop stability vs loading speed $\left(0.1 \mathrm{~mm} / \mathrm{min}\right.$ to $5 \mathrm{~mm} / \mathrm{min}$, or $\mathrm{R}=1 * 10^{-4}$ to $\left.8.3^{*} 10^{-3} \mathrm{~s}^{-1}\right)$ and temperature $(\mathrm{T}=295 \mathrm{~K}, 320 \mathrm{~K}$ and $335 \mathrm{~K})$. The consequent loops are shifted horizontally for the sake of clarity, in order to avoid overlaps.

Fig.4 presents the stress-strain elastic loops measured with different strain rates - from as slow as $0.1 \mathrm{~mm} / \mathrm{min}$ up to $5 \mathrm{~mm} / \mathrm{min}\left(\mathrm{R} \sim 1 * 10^{-4}\right.$ up to $\left.8.3^{*} 10^{-3} \mathrm{~s}^{-1}\right)$. At constant (room) temperature loops are identical, revealing an absolute stability with respect to the deformation speed in the mentioned range, at variance from the pseudoelasticity reported in SMA, due to stress induced phase transformation. Another crucial point for the possible technical applications is the temperature stability of the effect, evidenced on Fig.4, comparing the series of stress-strain loop measurements at elevated temperatures $(\mathrm{T}=320 \mathrm{~K}$ and $335 \mathrm{~K})$, compared with those made at $\mathrm{T}=295 \mathrm{~K}$. It can be clearly seen that the elastic behaviour (for alloy 2 ) is stable with temperature in the martensite phase, at least below $\mathrm{T}_{\mathrm{C}}$, except for the slight slope decrease due to the elastic modulus temperature dependence [17], according to the temperature dependence of the crystal lattice parameters of the martensite.

However, at present, it is not yet clear what the mechanism of a giant martensitic elasticity is. Further work is required to clarify the structural mechanisms and stability of the discussed phenomena. These studies have already started, utilising the in-situ studies with optical microscopy, X-ray and neutron diffraction under stress application, supported with Landau-based modelling approach, and will be submitted for publication in the nearest future.

The studied Ni-Mn-Ga compositions, alloy 2 (with tetragonal non-modulated martensite lattice) looks the most promising for possible technical applications, since it is much more ductile than others [18], making it capable of withstanding many cycles, and has high martensite transformation temperatures - i.e. wide temperature interval for actuation.

\section{Conclusions}

The phenomenon of giant linear completely elastic deformation $(>15 \%)$ in the martensite phase of Ni-Mn-Ga at ambient temperature was established.

The superelasticity effect is insensitive to the temperature deviation in the range $295 \mathrm{~K}-335 \mathrm{~K}$. The effect is not sensitive to the loading speed within the interval of 0.1 to $5 \mathrm{~mm} / \mathrm{min}\left(\mathrm{R} \sim 1 * 10^{-4}\right.$ to $\left.8.3 * 10^{-3} \mathrm{~s}^{-1}\right)$ and stable with continuous mechanical cycling. Alloys with a non-modulated tetragonal type of martensite lattice possess the highest elastic completely reversible deformations and have the widest principal temperature region.

The work was funded by the partner project P-279 between the European Office of Aerospace Research \& Development (EOARD), Science and Technology Centre of Ukraine (STCU) and Institute for Metal Physics of National Academy of Sciences of Ukraine. Authors are thankful to Prof. J.L. Martin (EPFL, Lausanne) for the help in the manuscript preparation, and to Prof. V.A. L'vov (Kiev, Ukraine) for fruitful discussions. 


\section{References}

[1] P.J. Webster, K.R.A. Ziebeck, S.L. Town, M.S. Peak, Philos. Mag. B. 49, 295 (1984).

[2] V.V. Kokorin, V.V. Martynov, V.A. Chernenko, Scr. Metall. Mater. 26, 175 (1992).

[3] V.A. Chernenko, V. L’vov, J. Pons, E. Cesari, J. Appl. Phys. 93, 2394 (2003).

[4] Y. Sutou, N. Kamiya, T. Omori, R. Kainuma, K. Ishida, K. Oikawa, Appl. Phys. Lett. 84, 1275 (2004).

[5] J. Wua, Q. Tian, Intermetallics 11, 773 (2003).

[6] Y.F. Zheng, B.M. Huang, J.X. Zhang, L.C. Zhao, Mater. Sci. Eng., A 279, 25 (2000).

[7] I. Schmidt, R. Lammering, Mater. Sci. Eng., A 378, 70 (2004).

[8] S. Kajiwara, W.S. Owen, Metall. Trans. 5, 2047 (1974).

[9] H. Kato, T. Ozu, S. Hashimoto, S. Miura, Mater. Sci. Eng., A 264, 245 (1999).

[10]F.J. Gil, J.M. Guilemany, Intermetallics 7, 699 (1999).

[11]L. Anand, M.E. Gurtin, J. Mech. Phys. Solids 51, 1015 (2003).

[12]D. Entemeyer, E. Patoor, A. Eberhardt, M. Berveiller, Int. J. Plast. 16, 1269 (2000).

[13] L. Orgeas, A. Vivet, D. Favier, C. Lexcellent, Y. Liu, Scr. Mater. 51, 297 (2004).

[14]H.B. Xu, Y. Ma, C. Jiang, Appl. Phys. Lett. 82, 3206 (2003).

[15] G. Mogylnyy, I. Glavatskyy, N. Glavatska, O. Söderberg, Y. Ge, V.K. Lindroos, Scr. Mater. 48, 1427 (2003).

[16] V.A. Chernenko, V. L’vov, J. Pons, E. Cesari, J. Appl. Phys. 93, 2394 (2003).

[17] V.A. Chernenko, J. Pons, C. Segu1, E. Cesari, Acta Mater. 50, 53 (2002).

[18] O. Söderberg, Y. Ge, A. Sozinov, S.-P. Hannula, V.K. Lindroos , Smart. Mater. Struct. 14, $223-235$ (2005). 